\title{
El artista modernista y el discurso psiquiátrico: Los Raros de Rubén Darío y la mirada médica finisecular
}

\section{The Modernist Artist and Psychiatric Discourse: Los Raros by Rubén Darío and the End-of-Century Medical View}

\author{
José Luis Gamarra La Rosa \\ Universidad Nacional de Tres de Febrero, Argentina \\ Pontificia Universidad Católica del Perú, Perú \\ jlgamarra@untref.edu.ar
}

\section{RESUMEN}

Este artículo se centra en la relación entre el discurso literario y el discurso psiquiátrico a finales del siglo xIx; especialmente, en lo que se refiere a la instauración de un saber sobre los anormales y la configuración de la genialidad artística como patología. El trabajo tiene como objetivo examinar la construcción de una "retórica de la enfermedad", sus estrategias y funciones, en Los Raros (1896-1905) de Rubén Darío, a partir del análisis del binomio conceptual normal/anormal y de la emergencia del discurso psiquiátrico como poder de normalización en las producciones artísticas. Para tal caso, se propone que los retratos literarios que traza Darío en dicha obra revelan una tensión entre dos tipos de mirada sobre lo normal y lo patológico. De un lado, está la de los artistas, con un discurso ambivalente que informa sobre un uso de la genialidad patológica como ideal estético; de otro, la de los psiquiatras, que instaura dispositivos de diagnóstico y de clasificación de los sujetos anormales. Darío hará frente a esta mirada clínica desde las páginas de sus retratos literarios, mediante un discurso que desmonta la episteme del discurso médico-psiquiátrico y cuestiona el lugar fluctuante que ocupan los escritores modernistas en la incipiente sociedad de consumo del Buenos Aires finisecular.

Palabras clave

Modernismo, Rubén Darío, Los Raros, genialidad artística, enfermedad, decadentismo, degeneración.

\section{ABSTRACT}

This article focuses on the relationship between literary discourse and psychiatric discourse in the late 19th century; especially, in what refers to the establishment of 
knowledge about the abnormal and the configuration of artistic genius as a pathology. Furthermore, the work aims to examine the construction of a "rhetoric of the disease", their strategies and functions, in Los Raros (1896-1905) by Rubén Darío, from the analysis of the normal/abnormal conceptual binomial and the emergence of psychiatric discourse as power of normalization in end-of-century artistic productions. The author proposes that the literary portraits that Darío draws in his work reveal a tension between two types of gaze on the normal and the pathological. On the one hand, the artistic gaze of end-of-century artists with an ambivalent discourse that informs about a use of a pathological genius as an artistic ideal; on the other, the psychiatric gaze, which establishes a series of diagnostic and classification devices for abnormal subjects. Darío will face this clinical gaze from the pages of his literary portraits through a discourse that dismantles the episteme of the medical-psychiatric discourse and questions the fluctuating place that modernist writers occupy in the incipient Buenos Aires consumer society.

\title{
KEYWORDS
}

Modernism, Rubén Darío, Los Raros, artistic genius, disease, decadentism, degeneration.

RECEPCIÓN: 28/06/2020

ACEPTACIÓN: 30/08/2020

Un libro no es importante por las cosas que remueva, sino cuando el lenguaje, a su alrededor, se desarregla, habilitando un vacío que se convierte en su lugar de residencia.

Foucault

Todo lo que es profundo ama la máscara.

Nietzsche

\begin{abstract}
7 xiste una relación evidente entre el discurso literario y el discurso médico-psiquiáUtrico a finales del siglo xix; principalmente, en lo que se refiere a la instauración de un saber clínico sobre los sujetos anormales y a la configuración de la genialidad artística como patología. ${ }^{1}$ En su crónica "Manicomio de artistas — Degeneración -
\end{abstract}

\footnotetext{
${ }^{1}$ Para el último tercio del siglo xIx, el discurso psiquiátrico en la Argentina se presentaba como un saber emergente que buscaba posicionarse en el campo médico dominado por los principios positivistas de la fisiología-experimental. En La palabra médica en la Argentina (18901910), Pablo von Stecher propone que "la Psiquiatría, como disciplina científica y práctica, adquirió un prestigio nuevo entre los sectores tradicionales de la sociedad hacia fines del siglo.
} 


\section{El artista modernista y el discurso psiquiátrico}

La última obra de Max Nordau" (1894), Rubén Darío propone una fórmula intuitiva y sugerente para dar sentido a esta relación: "en tanto que la literatura investiga y se deja arrastrar por el impulso científico, la medicina penetra al reino de las letras; se escriben libros de clínica tan amenos como una novela. La psiquiatría pone su lente práctico en regiones donde solamente antes había visto claro la pupila ideal de la poesía" (Darío, 2015: 132). El aforismo entabla diversas relaciones intertextuales con documentos y debates de la época, entre los cuales se destaca el vínculo manifiesto entre el naturalismo literario y el discurso fisiológico-experimental, pero, más allá de esto, la sentencia sugiere una querella sobre la validez de la mirada, "lente práctico" o "pupila ideal", la interferencia de estilos y el lugar del poeta en la modernidad.

En ese sentido, el objetivo del presente trabajo es examinar la construcción de una "retórica de la enfermedad", sus estrategias y funciones, en Los Raros (1896-1905) de Rubén Darío, a partir del análisis del binomio conceptual normal/anormal y de la emergencia del discurso psiquiátrico como poder de normalización en las producciones artísticas del fin-de-siglo. En este contexto, marcado por la universalización de una cultura cientificista, se difundirá la noción de degeneración anudada a las propuestas de Bénédict A. Morel y Cesare Lombroso, que servirán — siguiendo a Michel Foucault - de "marco teórico, al mismo tiempo que de justificación moral y social, a todas las técnicas de señalamiento, clasificación e intervención referidas a los anormales" (Foucault, 2014: 301). Según se observará más adelante, dicha teoría fue empleada en tratados como Degeneración (1892-1893) del médico y escritor austro-húngaro Max Nordau (1849-1923) para explicar los fenómenos patológicos vinculados al campo artístico. Los retratos literarios que conforman Los Raros resisten la construcción de estos diagnósticos clínicos, mediante un proceder retórico que desmonta la episteme del discurso médico-psiquiátrico y cuestiona el lugar fluctuante que ocupan los escritores modernistas en la incipiente sociedad de consumo del Buenos Aires de fin de siglo.

La noción de "retórica de la enfermedad" asociada al campo artístico ha recorrido diversos usos y definiciones. Susan Sontag propone, por ejemplo, que "las metáforas patológicas siempre han servido para reforzar los cargos que se le hacen a la sociedad por su corrupción o injusticia" y, de esta manera, "expresar una preo-

El problema de la locura atrajo la atención de intelectuales y políticos, y la aplicación de conceptos psicopatológicos excedió ampliamente el ámbito médico" (Stecher, 2017: 23). No obstante lo expuesto, es de notar que la terminología para designar a los nuevos estudios de patología mental fue considerablemente variable por estos años. Así, un lector tan prevenido como Paul Groussac empleará indistintamente los términos "escuela psiquiátrica moderna", "novísima psicología científica" o "psico-patología contemporánea" para referirse a los avances de esta nueva formación discursiva. Al respecto, véase la "Introducción" de Groussac a La locura en la historia (1895) del médico, escritor y político argentino José María Ramos Mejía (1849-1914). 
cupación por el orden social" (Sontag, 2016: 87). En el campo literario hispanoamericano, estos usos se han relacionado, sobre todo, con el desarrollo del naturalismo, el decadentismo y el modernismo. Al respecto, Gabriela Nouzeilles ha indicado que en la retórica modernista de la enfermedad "lo que se cuestionaría no sería tanto el concepto de 'salud' en sí como la misma oposición fundacional entre lo normal y lo patológico. De este modo, la marca absoluta de la autonomía no consistiría tanto en invertir un orden [de valores] sino más bien en disolver el juego binario del racionalismo moderno" (Nouzeilles, 1997: 154). Por su parte, Ana Laura Zavala Díaz ha resaltado, en el México porfiriano, el empleo de esta imaginería patológica para exponer el malestar de los escritores frente a "la conflictiva situación del artista en el mundo modernizado" (Zavala, 2007: 168). De esa manera, siguiendo a la autora, la apropiación del discurso patológico sirvió a los escritores de la segunda generación modernista para "ingresar oficialmente al sistema literario, así como para proponer otras formas de organización y funcionamiento de éste" (Zavala, 2018: 96).

En el presente artículo se entiende por "retórica de la enfermedad" a la apropiación del archivo médico y, particularmente, de la sintaxis del caso clínico que efectuaron los escritores modernistas - ligados a la formación estética del simbolismo y decadentismo francés - para develar las contradicciones, los mitos y los modos de ver de una sociedad de normalización que se ha construido sobre la base de una lógica de dominación e imposición simbólica. Desde una óptica arqueológica centrada en la exploración de la mirada médico-psiquiátrica (Foucault, 2014), lo que nos interesa es pensar cómo han funcionado ciertos enunciados vinculados a la enfermedad, "qué efectos han producido, cómo y dónde han circulado, quiénes y contra quién han sido sostenidos o denigrados" (Murillo, 1996: 7). En la obra dariana, la apropiación de dicha retórica se observa una década antes de la publicación de la primera edición de Los Raros (Buenos Aires: La Vasconia, 1896). Así, en la nota periodística "Apuntaciones y párrafos" (aparecida originalmente en La Época, Santiago, 3 de diciembre de 1886), Darío señalaba con relación al escritor decadente Maurice Rollinat (18461903) que era un "poeta melancólico", a quien la crítica calificaba de "poeta enfermo". Y agregaba: "Sí, enfermo, muy enfermo de aquel mal incurable que padeció Heine, que sufrió Baudelaire [...] neurosis misteriosa, de la cual están libres los que no tienen más que pura masa cerebral entre las cuatro paredes del cráneo" (Darío, 1934: 69). La breve nota sobre el poeta francés, que años más tarde ampliará Darío en su crónica "Las tinieblas enemigas - La muerte de Rollinat", incluida en Opiniones (1906), muestra un primer acercamiento del poeta nicaragüense a los mecanismos retóricos de la enfermedad como instrumento de subversión del archivo clínico aplicado al estudio de la literatura.

Dicho texto periodístico, "Apuntaciones y párrafos", tiene su correlato ficcional en el cuento "El pájaro azul" (La Época, Santiago, 7 de diciembre de 1886), publica- 


\section{El artista modernista y el discurso psiquiátrico}

do apenas unos días después en el mismo diario e incluido posteriormente en $A z u l \ldots$ (1888). Allí se presentaba el "caso" del joven poeta Garcín, "triste casi siempre”, quien padecía una enfermedad mental recientemente documentada en los tratados médicos de inicios de siglo: la monomanía. ${ }^{2}$ En el relato se lee: "un alienista a quien se le dio noticia de lo que pasaba, calificó el caso como una monomanía especial. Sus estudios patológicos no dejaban lugar a duda. Decididamente, el desgraciado Garcín estaba loco" (Darío, 2016: 207). Los dos textos referidos, la nota y el cuento, son una muestra temprana de la apropiación de la sintaxis clínica en la formación discursiva de Darío. ${ }^{3}$ No obstante, la mayor persistencia de la retórica de la enfermedad en su obra se manifestará recién en su etapa rioplatense (1893-1898), sobre todo, a partir de la publicación de la crónica-retrato destinada al comentario crítico de Max Nordau, texto que será analizado minuciosamente en uno de los apartados de este trabajo. Al respecto, José María Martínez ha resaltado, en relación con la arquitectura de Los Raros, que "la lectura de Degeneración de Nordau parece haber sido el detonante del título y el origen último del libro" (Martínez, 2016-2017: 86). A continuación, nos proponemos situar el volumen de retratos literarios de Darío en su contexto inmediato de producción, es decir, en el Buenos Aires de finales del siglo xIx. Nos detendremos puntualmente en la cuestión del imperativo del discurso médico positivista y su hegemonía en el proceso modernizador.

${ }^{2}$ Según Rafael Huertas: "La monomanía [sobre todo a partir de la obra de Esquirol (17721840)] se convierte así en un instrumento político de primer orden; por un lado, porque facilitaba un 'cajón de sastre' — uno más en la historia de la psiquiatría - con que diagnosticar actitudes o actividades que atentaran contra el orden establecido. Por otro, porque dieron la posibilidad a los médicos de afianzar su prestigio" (Huertas, 1991: 20).

${ }^{3}$ Vale recordar que la imaginería patológica de la enfermedad mental acompañó las figuraciones y auto-figuraciones de Darío desde el inicio de su actividad como cronista y poeta. En su presentación como corresponsal de La Nación, por ejemplo, se destacará - transcribiendo lo dicho por Eduardo de la Barra en el "Prólogo" de Azul... (en Darío, 1888: III) — su "temperamento artístico [...] de gusto fino y delicado, casi diría aristocrático; neurótico y por lo mismo original" ("Rubén Darío", 1889: 1). En cuanto a las auto-figuraciones del poeta, resalta la expuesta en el poema "Epístola", dedicado a la señora de Leopoldo Lugones, incluido en El canto errante (1907): "Quiero decir que me enfermé. La neurastenia / es un dón que me vino con mi obra primigenia" (Darío, 1907: 131). En contraposición con estas figuraciones artísticas de lo patológico, Nordau proponía, en Psico-fisiología del genio y del talento, que "en opinión de un gran número de alienistas, el genio es una neurosis [...] Yo creo que éste es un error que tiene su punto de partida sobre todo en una aplicación tradicional, pero inexacta, de la palabra genio; se llama así, con una deplorable facilidad, á cualquier imbécil extático que se las echa de profeta ó de artista" (Nordau, 1901: 117). 


\section{Buenos Aires: escritura y enfermedad en el fin de siglo}

Para 1893, año en que la galería de Los Raros entra en circulación, los límites entre el discurso literario y el discurso médico eran borrosos en la ciudad porteña. La fascinación por los casos clínicos — su diagnosis, su etiología y su prognosis - originó la proliferación de una serie de relatos centrados en el cuerpo enfermo, el temor al contagio y un complejo sistema de mecanismos de regulación y exclusión social (véanse Vezzetti, 1985; Salessi, 1995; Nouzeilles, 2000; Terán, 2000; Bruno, 2012; Stecher, 2017). Asimismo, los programas higienistas, los ensayos nacionalistas y las ficciones literarias - especialmente aquellas cercanas a los principios del naturalismo - compartían una práctica discursiva en común, en la cual abundaban las metáforas fisiopatológicas sobre el cuerpo ciudadano y los sujetos anormales o degenerados. Las ciudades eran pensadas e imaginadas como organismos enfermos que una élite cultivada en los nuevos procedimientos de las ciencias experimentales debía regenerar. A decir de Gabriela Nouzeilles — quien analiza las implicaciones del discurso médico en las ficciones naturalistas argentinas - , entre los años de 1880 y 1910, "el saber médico se convirtió en el modelo epistemológico hegemónico con el cual producir conocimiento acerca de lo social" (Nouzeilles, 2000: 35). De esto se puede inferir que la sintaxis clínica se encargó de dar legibilidad a una serie de procesos sociales, económicos y demográficos desde una racionalidad positiva e instrumental.

$\mathrm{Al}$ respecto, el médico, escritor y político argentino Eduardo Wilde anotaba - en su Curso de hïiene pública (1878) - que "es evidente que hay una relación entre los gobiernos y la medicina, es decir, entre el poder social y la medicina en función” (Wilde, 1878: 20). Así, "todo acto médico higienista, es un acto de perito que sirve para instruir a la autoridad, enseñándole el modo como ha de proceder en circunstancias dadas" (Wilde, 1878: 21). De esta manera, se puede observar cómo la consolidación del Estado-nación en la Argentina, al igual que en gran parte de Occidente, estuvo sujeta en el último tercio del siglo xix a la difusión de dos relatos clínicos complementarios: el de la profesión médica como custodia del cuerpo ciudadano y el de la desaparición definitiva de las enfermedades como materialización del ansiado progreso (véanse Nouzeilles, 2000: 35; Vezzetti, 1985: 14; Bruno, 2012: 82; Stecher, 2017: 71). En cuanto a este punto, Hugo Vezzetti ha rastreado el establecimiento, en la década de los ochenta, de un dispositivo sanitario y de higiene pública - organizado en instituciones específicas y en un sistema ideológico sustentado en la teoría de la degeneración- que reescribe los proyectos políticos de la élite criolla en términos científicos, a través de la instauración de una tecnología médica modelada según los protocolos europeos: "ese proceso que en Francia lleva décadas, en la Argentina se consuma en pocos años" (Vezzetti, 1985: 154). De esa manera, la medicalización del aparato estatal — provista en las disposiciones de orden jurídico, penal y pedagógico - tenía 


\section{El artista modernista y el discurso psiquiátrico}

como objetivo la regulación de la población y la constitución de un sujeto socio-moral ideal que resguardara al cuerpo ciudadano de los efectos no deseados del progreso.

Esta incidencia de la mirada médica en el campo político y cultural argentino - y su reacomodo a diferentes modelos textuales e intereses particulares - se corrobora igualmente en la amplia difusión de textos médico-psiquiátricos que circulaban en la prensa y en el ámbito académico. La escritura clínica se transformó así en el soporte de una "cultura científica", que legitimaba sus prácticas en un doble movimiento: por un lado, a través del estatuto técnico-experimental de sus producciones (Terán, 2000: 85); por otro, a partir de la construcción de una imagen de médico-académico sustentada en su saber letrado (Stecher, 2017: 79 y ss.). A modo de ejemplo, se podrían traer a colación numerosos textos que han leído la historia, la sociología y la literatura desde un discurso de pretensiones positivistas. Dentro de ese corpus, se fijarán dos obras clínicas que dialogan en diversos grados con la galería de Los Raros: los tratados de enfermedades nerviosas Las neurosis de los hombres célebres en la historia argentina (1878-1882) de José María Ramos Mejía y Pasiones. Estudios médico-sociales (1893) de Lucas Ayarragaray. El libro de Ramos Mejía difundió en el campo cultural argentino la noción de neurosis aparejada a la explicación de los llamados "estados intermedios", donde convergen la enajenación mental y la iluminación profética. En el tratado clínico, se lee: "son, puede decirse, una confusión de luz y de sombras, una mezcla incomprensible de la salud y de la enfermedad, una combinación extraña de la razón y la locura" (Ramos, 2013: 132). Así, este pasaje del tratado clínico parece dialogar con la descripción que se ofrece del poeta portugués Eugenio de Castro en el último párrafo de Los Raros: "Se trata, pues, de un 'raro'. Y será asombro curioso el de aquellos que lean a Eugenio de Castro con la preocupación de moda de los epidérmicos que creen que toda obra simbolista es un pozo de sombra. Belkiss está lleno de luz" (Darío, 2015: 410). El médico, historiador y político argentino Lucas Ayarragaray (1861-1944), por su parte, citado en Los Raros como autor de una obra digna de elogio, dialoga directamente con muchos pasajes darianos, en particular en lo referente a la concepción del artista semi-loco, necesario para "la evolución del progreso humano" (Ayarragaray, 1893: 11), y la enajenación mental como ingreso privilegiado a la imaginación poética: "de semejante desequilibrio de espíritu nacen las tendencias geniales" (Ayarragaray, 1893: 11). En ambos casos, se trata de documentos conjeturales destinados a fundar una relación ambigua entre la locura y la genialidad. La mirada médica concibe aquí al texto (histórico o social) como un cuerpo que debe ser observado en busca de los signos o estigmas degenerativos. La mirada es la que guía y regula la interpretación del cuerpo textual y establece una analogía entre los signos "observables" y su correlato moral anómalo. Como se verá en el siguiente apartado, Darío invierte la lógica del discurso médico en un gesto que pretende redimir a los artistas finiseculares y recolocar a la escritura frente al desarreglo de saberes institucionalizados. 


\section{Manicomio de artistas: genialidad, enfermedad y locura}

El 8 de enero de 1894 aparece, en el diario La Nación de Buenos Aires, la primera versión de la crónica-retrato que Rubén Darío dedica al médico austrohúngaro Max Nordau, con el sugerente título de "Manicomio de artistas - Degeneración — La última obra de Max Nordau". A los pocos días, la crónica se reproduce en el diario La Razón de Montevideo y, posteriormente, en las dos ediciones de Los Raros (Buenos Aires, 1896; Barcelona, 1905), con cuantiosas variantes tipográficas, ortográficas y escasas, pero significativas, modificaciones semánticas que dan cuenta de la génesis del texto. ${ }^{4}$ Esta crónica inicia uno de los debates más persistentes en la obra periodística y programática de Darío, que proseguirá con escritos de ida y vuelta, entre el poeta y el médico, en las páginas de La Nación. ${ }^{5}$ Dicha polémica actualizará diversos tópicos sobre la impronta del arte simbolista-decadente y las psicopatías artísticas en el fin-de-siglo.

En La intertextualidad literaria (2001), José Martínez Fernández resalta que el título de un texto "es la puerta de entrada al mismo y origina un 'horizonte de expectativas' determinado". El autor agrega, además, que "con no rara frecuencia el escritor, el poeta, acude al campo abonado de la literatura, donde halla versos o títulos anteriores que decide aprovechar con diferente actitud (respetuosa, indiferente, irónica, lúdica, polémica, etc.)" (Martínez Fernández, 2001: 136). A partir de esto, se podría

\footnotetext{
${ }^{4}$ La crónica publicada en La Nación (Darío, 1894) se reprodujo en La Razón de Montevideo el martes 16 de enero de 1894, edición de la mañana. Entre las elisiones más significativas de la crónica, se puede resaltar la supresión de dos fragmentos en la edición en libro: 1) en relación con la genialidad de Rimbaud, se elimina "fue un loco peligroso que sanó, y cuya prosa y versos babélicos, al diablo que los digiera" (Darío, 2015: 139-140); 2) con respecto a los "excéntricos literatos" - Tristan Corbière, René Ghil y Gustavo Kahn-, se suprime "que proceden pour épates les bonsgeoises [sic]" y se añade "llevados por una concepción del arte, en verdad abstrusa y difícil" (Darío, 2015: 140). La expresión francesa "épater le bourgeois" - dejar al burgués patidifuso o atónito - fue un tópico en la literatura del fin-de-siglo. Su empleo se asociaba a una crítica no exenta de ironía del predominio del orden burgués (Sobejano, 2009). Esta última variante da cuenta, junto con la modificación del título, de la progresiva atenuación del tono beligerante de la crónica en sus sucesivas versiones.

5 "Nuestros colaboradores - Max Nordau" (La Nación, 24 de abril de 1901), artículo firmado por Rubén Darío que ameritará la repuesta dos años después del médico, "Lo que se gana con tener razón" (La Nación, 5 de marzo de 1903), y la réplica del poeta, "Al Dr. Max Nordau" (La Nación, 14 de mayo de 1903). En este sentido, en "Dilucidaciones", prólogo de El canto errante (1907), Darío comentará: "Tanto en Europa como en América se me ha atacado con singular y hermoso encarnizamiento [...] Tan solamente he contestado a la crítica tres veces, por la categoría de sus representantes, y porque mi natural orgullo juvenil, jentonces! recibiera también flores de los sagitarios. Por lo demás, ellos se llamaban Max Nordau, Paul Groussac, Leopoldo Alas" (Darío, 1907: XVI-XVII).
} 


\section{El artista modernista y el discurso psiquiátrico}

repensar en las transformaciones que sufrió el título de la crónica, en su paso del texto periodístico al volumen en libro, como evidencia de un desarrollo estético en el que el rasgo más evidente es la atenuación del remarcado tono irónico. Las variantes del título se presentan como sigue: en La Nación, lunes 8 de enero de 1894 (p. 4, cols. 1-3), se consigna el título: "Manicomio de artistas - Degeneración - La última obra de Max Nordau”. En La Razón, Montevideo, martes 16 de enero de 1894 (p. 1, cols. 3-5), se reproduce el mismo título con ligeras variantes tipográficas. En su paso de la versión periodística a la edición en libro, el título cambia de modo significativo: en la primera edición de Los Raros (Darío, 1896: 117-128), un lema antecede al nombre del médico: "La encarnación de Bonhomet / Max Nordau". En la segunda edición, "corregida y aumentada", de Los Raros (Darío, 1905: 191-202), únicamente se muestra el título: "Max Nordau".

El título original no sólo evidencia la inmediatez del texto periodístico, sino también del potencial irónico de una imagen patológica y represiva materializada en el término "manicomio". Al respecto, el tratado clínico reseñado en el diario se presentaba como un espacio de confinamiento para el saber artístico. El lema que antecede al título de la primera edición en volumen refuerza esta idea y coloca al autor del tratado en una posición ambigua respecto a la validez de su saber clínico. El lema genealógico, "La encarnación de Bonhomet", metaforiza la figura del médico austrohúngaro: Nordau es Bonhomet. De este modo, el título equipara al autor de Degeneración con un personaje de ficción pavorosamente cruel, como era el científico loco ideado por Villiers de L'Isle-Adam en su libro Tribulat Bonhomet (1887). En las páginas de Los Raros, se lee que Bonhomet "es una especie de Don Quijote trágico y maligno, perseguidor de la Dulcinea del utilitarismo y cuya figura está pintada de tal manera, que hace temblar" (Darío, 2015: 203). La mediación del personaje de ficción para describir a Nordau permite cuestionar la naturaleza incierta de sus diagnósticos médico-estéticos y da cabida a una lectura en clave irónica de la crónica-retrato. ${ }^{6}$

${ }^{6}$ Esta atenuación de elementos irónicos en la versión definitiva de Los Raros, respecto a la representación del médico austrohúngaro, estará presente también en otros textos del volumen. Así, en la crónica dedicada a Paul Verlaine - La Nación, 10 de enero de 1896-, se hace alusión al facultativo del siguiente modo: "Cuando el 'humorista' judío Nordau publicó la obra célebre" (Darío, 2015: 353). En la versión del libro de 1896, se eliminará el calificativo de 'humorista', y en la de 1905, se suprimirá además la designación de "judío", quedando la expresión reducida a: "Cuando el Dr. Nordau publicó [...]”. Cabría preguntarse, entonces, ¿de qué forma la atenuación de la carga irónica en las sucesivas ediciones de los textos da cuenta de un giro en la propuesta estética del volumen final? Y, ¿hasta qué punto el proyecto estético trazado en Los Raros muestra sus límites espacio-temporales en relación con estas modificaciones semánticas? Se puede conjeturar, de manera preliminar, que las variantes en los títulos son un indicio de un viraje en el programa estético dariano o, por lo menos, un reacomodo de sus presupuestos acráticos y combativos respecto a la figura del autor de Degeneración. 
Prosiguiendo con el análisis textual, es interesante observar la disposición meticulosa con que Darío selecciona y distribuye la información al interior de su crónica. Para examinar dicho arreglo, se procederá a dividir el texto en cinco segmentos, a los cuales se le asignará un título que ilustre, de modo sucinto, su contenido. Esta segmentación permitirá mostrar la coherencia estructural del discurso cronístico. La primera sección comprende el párrafo inicial y corresponde a la introducción del texto, que podríamos titular "El tipo del médico moderno y el artista degenerado". En ella, se establece una confrontación inicial entre la mirada médica y la mirada artística, a partir de un discurso que apela a un proceder irónico y a la hipérbole de los hallazgos clínicos sobre la locura: "Max Nordau no deja un solo nombre, entre todos los escritores y artistas contemporáneos, de la aristocracia intelectual, al lado del cual no escriba la correspondiente clasificación diagnóstica: 'imbécil', 'idiota', 'degenerado', 'loco peligroso" (Darío, 2015: 129). Frente a esta mirada clínica que invade el campo literario, la crónica contrapone la mirada artística, que se apropia de la retórica de la enfermedad como instrumento desestabilizador de ese saber/poder. Este primer segmento se cierra con un aforismo, que sintetiza tal pugna: "Cuando la literatura ha hecho suyo el campo de la fisiología, la medicina ha tendido sus brazos a la región obscura del misterio" (Darío, 2015: 130). La sentencia permite observar la competencia de saberes por la especialización sobre un mismo objeto de discurso: "la región obscura del misterio", esto es, el mundo de las pasiones y de la psiquis humana. ${ }^{7}$

La segunda sección comprende los párrafos 2 y 3, que podrían titularse "La historia secreta de la contienda entre la medicina y la literatura”. En ella, se presenta un recuento histórico de los ataques de la República de las Letras contra el saber médico. Se pasa revista a la obra satírica de Molière y Lesage en los siglos XVII y XVIII, respectivamente, hasta llegar a la relación entre el discurso médico de Claude Bernard -Introducción al estudio de la medicina experimental (1865) - y la propuesta naturalista de Émile Zola en el siglo XIX. El apartado concluye con el siguiente juicio: "En tanto que la literatura investiga y se deja arrastrar por el impulso científico, la medicina penetra al reino de las letras; se escriben libros de clínica, tan amenos como una novela. La psiquiatría pone su lente práctico en regiones donde solamente antes había visto claro la pupila ideal de la poesía" (Darío, 2015: 132). El aforismo, al igual que el que cierra el segmento anterior, resume las principales líneas de esta querella. En ese sentido, nos permite observar la irrupción del discurso psiquiátrico como lente a través del cual se empiezan a leer los otros saberes: el estético, el religioso, el político o el ético.

La tercera sección está conformada por los párrafos que van del 4 al 7, cuyo título sería "La nueva crítica científica y los artistas peligrosos". Ahí, se exponen los procedi-

${ }^{7}$ En La arqueología del saber, Foucault ha trazado la manera en la que la locura se constituye, en el siglo XIX, como "objeto del discurso" del saber psiquiátrico (Foucault, 2002: 65 y ss.). 


\section{El artista modernista y el discurso psiquiátrico}

mientos de la "nueva crítica científica" sustentada en los hallazgos de la ciencia penal y en el análisis comparativo de las patologías sociales y morales. En este segmento, la crónica advierte sobre la vinculación tendenciosa entre literatura, estados patológicos y sujetos peligrosos que se viene gestando en los nuevos estudios de sociología del arte. Al respecto, se alude al trabajo de Jean-Marie Guyau, El arte desde el punto de vista sociológico (1902 [1888]), del cual se comenta por extenso el sexto capítulo, titulado "La literatura de los decadentes y los desequilibrados; su carácter generalmente insociable. Función moral y social del arte". Guyau afirma allí que "los rasgos característicos de la literatura de los trastornados, se encuentran en la de los criminales y los locos, que nos han hecho conocer recientemente los trabajos de Lombroso, de Lacassagne y los criminalistas italianos" (Guyau, 1902: 469). En esta sección, la crónica desmonta los argumentos formulados por los científicos sociales sobre los supuestos estigmas patológicos que mostraban los artistas de fin-de-siglo. El problema que observa Darío en los planteamientos del "analizador sociológico" es su falta de conocimiento de la tradición literaria y su empleo utilitario de las categorías provistas por la nueva ciencia penal.

El cuarto segmento comprende los párrafos que van del 8 al 16, y podría llevar el encabezado "Los condenados por degeneración artística". En esta parte, se pasa revista a los artistas y escritores incluidos por Nordau en sus diagnósticos clínico-estéticos por sufrir de alguna patología mental vinculada al arte. La crónica apela a la tradición literaria para desarticular los argumentos nosológicos del médico austrohúngaro. Así, frente al diagnóstico impuesto a Dante Gabriel Rossetti, por padecer de una aparente patología rítmica, ${ }^{8}$ Darío señala que: “deben acompañar lógicamente en su desahucio, al exquisito, prerrafaelita, los bucólicos griegos, los autores de himnos medioevales, los romancistas españoles y los innumerables cancioneros que han repetido por gala rítmica una frase dada en el medio o en el fin de sus estrofas" (Darío, 2015: 138). La retórica de la enfermedad sirve aquí para desenmascarar la posición ambigua de la mirada médica ante las manifestaciones del arte moderno. A partir del párrafo 13, dedicado al "egotismo" - etiqueta bajo la que se agrupa a "parnasianos", "diabólicos", "decadentes", "estetas", "ibsenistas" y a Nietzsche-, inicia propiamente la reseña del segundo tomo de Degeneración, asunto que en la introducción se presentaba como el motivo central de la crónica. Aquí resalta la mención al libro Intenciones (1891) de Oscar Wilde, paradigma de la "crítica artística", 9 que funciona en el texto como un contraejemplo de la implementación de la crítica cientificista en el fin-de-siglo.

${ }^{8}$ Según Nordau: "Esta singularidad del lenguaje de los idiotas y de los dementes — la ecolalia - la hallamos con frecuencia en Rossetti" (Nordau, 1902, t. I: 146).

${ }^{9}$ Darío emplea esta terminología, además, en su crónica sobre las obras Esquisses y Sensaciones de Arte de Enrique Gómez Carrillo; "crítica artística" que muestra como signo distintivo el trabajo sobre el estilo. Allí se lee: "El estudio sobre el arte de la crítica es digno de llamar la atención, por la idea nueva que trae, por el intento que encierra" (véase Darío, 1893: 2-3). 
La última sección de la crónica la conforman los dos párrafos finales, 17 y 18, que podríamos titular "Un método analítico delirante". Aquí se resume el método aplicado por Nordau en su tratado de nosología artística. Mediante un proceder irónico, la crónica cuestiona los principios que sirven de sustento a los planteamientos del tratado clínico. Por ejemplo, en relación con el diagnóstico que el médico efectúa de la degeneración de los artistas fin-de-siglo, se explica: "cuando [Nordau] trata de la curación debe permitir que sus lectores abran la boca en forma de O... Receta: prohibición de la lectura de ciertos libros, y, respecto a los escritores 'peligrosos', que se les aleje de los centros sociales, ni más ni menos como a los lazarinos y coléricos" (Darío, 2015: 144-145). Esta sección acerca nuevamente la figura de Nordau a la de su doble ficcional, el doctor Tribulat Bonhomet, para dejar expuesto que el primero opera con una mecánica aún más despiadada que el segundo. ${ }^{10}$

Como aspecto adicional a la organización de la crónica, cabe precisar que Darío construye su punto de partida mediante una relación dialógica con un texto previo: la crónica-reseña del doctor Wilhelm Schimper (1856-1901), aparecida casi un año antes, sobre el primer volumen de Degeneración (1892) de Max Nordau. ${ }^{11}$ La crítica de Schimper se incluye en dos entregas en La Nación, dentro de sus correspondencias enviadas desde Alemania. ${ }^{12}$ El motivo de la crónica de Darío es, por tanto, la publicación del segundo volumen del tratado clínico puesto en circulación a finales de 1893 . No obstante, como se ha señalado líneas arriba, la mayor parte del escrito se dedica a comentar el primer volumen de Degeneración. ¿Qué le interesa a Darío de este texto médico? ¿Qué tanto repite lo expuesto por Schimper y qué tanto complementa el

${ }^{10} \mathrm{Al}$ respecto, se lee al final de la crónica: "el viejo Tribulat no era tan cruel, pues ofrecía dar a sus condenados a aplastamiento, más horizontes bellos, aires suaves, músicas armoniosas. Por tanto, yo, que adoro al amable coro de las musas, y el azul de los sueños, preferiría antes que ponerme en manos de Max Nordau, ir a casa del médico de Clara Lenoir [es decir, del médico de ficción]" (Darío, 2015: 146).

${ }^{11}$ El 29 de junio de 1893 aparece en La Nación un perfil dedicado al doctor Wilhelm Schimper. En él, se indica que sus "cartas de Alemania, con proporciones de revista y profundidad de monografía, son leídas y comentadas por su novedad, por su independencia absoluta, y por el acierto que campea en ellas [...] su autor borra en ellas el límite de las artes y de las ciencias, para ocuparse de cuanta cuestión se agita en el campo de la inteligencia y el saber" ("El Dr. Schimper": 1). Según la nota, su carrera periodística inicia en el fornal do Brazil. A partir de 1892, se convierte en corresponsal exclusivo de La Nación. Sus cartas versan sobre "la Alemania actual y los países vecinos, en lo que respecta a la sociabilidad, arte, ciencia y literatura" "“El Dr. Schimper": 1).

${ }^{12} \mathrm{Si}$ bien las dos crónicas de Schimper se ocupan en su mayor parte de comentar el primer volumen de Degeneración, no se centran exclusivamente en la obra de Nordau. Para las referencias precisas de los artículos, véase la bibliografía final. 


\section{El artista modernista y el discurso psiquiátrico}

comentario de los dos volúmenes? ${ }^{13}$ Sobre este último punto es importante advertir que las posiciones relativas a la cuestión estética del fin-de-siglo de Darío y Schimper son contrapuestas. El médico apela a una mirada positiva, podría decirse utilitaria del lenguaje, desde la cual cuestiona el hermetismo discursivo de los artistas finiseculares. Al inicio de su primera carta, por ejemplo, al referirse a Ibsen, indicará: “¡Por qué diantres esos autores que se dicen profundos no escribirán como todo el mundo, dando a cada palabra su sentido propio y exacto [...]! Os confesaré que, en cuanto a mí, sólo veo en eso fumesteria, humbug y snobismo" (Schimper, 1893a: 1). Schimper se aleja, de igual modo, de los juicios de Nordau sobre el nuevo arte y su análisis de la sociedad francesa: "Degeneración, un libro muy claro, pero nada profundo, escrito por un filisteo inteligente e instruido" (Schimper, 1893a: 1). El campo literario del fin de siglo estaba saturado de obras que incidían en la relación entre literatura y enfermedad. En el ámbito hispanoamericano, este hecho queda ilustrado en títulos como Literaturas malsanas. Estudios de patología literaria contemporánea (1894) del escritor español Pompeyo Gener o La psicopatología en el arte (1920 [1899]) del escritor y médico argentino José Ingenieros.

La crónica dariana abunda en relaciones intertextuales con textos clínicos como el de Schimper. En el artículo sobre Nordau, se puede observar la mención a numerosos estudios médico-estéticos (como los de Ayarragaray, Guyau o Thorel), así

${ }^{13}$ Según se advierte en su minuciosa edición crítica de Los Raros, Schmigalle duda de que Darío haya podido leer de primera mano el libro que reseña: "Los dos volúmenes de la versión francesa, traducidos por Auguste Dietrich, con fecha de 1894, en enero de aquel año todavía no habían llegado a las librerías de Buenos Aires" (Schmigalle en Darío, 2015: 128). No obstante, queda la posibilidad de que Darío tuviese acceso a la versión italiana de 1893 o de que fuese informado del contenido del segundo volumen a través de otras fuentes. En este sentido, lo más probable es que el nicaragüense tuviera conocimiento de las polémicas en torno a Degeneración aparecidas en diversos medios franceses de aquellos años. Así, en su crónica sobre Nordau se deja constancia de la lectura del artículo de Jean Thorel, "Une nouvelle méthode de critique (1) - M. Max Nordau", publicado en la Revue Politique et Littéraire. Revue Bleue el 12 de agosto de 1893, que comenta ampliamente los dos volúmenes de Degeneración (Thorel, 1893: 208-214). Véase, además, el diario Le Ménestrel del 17 de diciembre de 1893, en donde se da noticia del primer tomo de la mencionada traducción francesa: "las teorías de M. Nordau, serán discutidas, sus juicios pueden ser gravados de severidad excesiva, pero nadie discutirá que su libro es de una lectura atrayente" (406; la traducción es mía). De igual forma, en la revista La Plume del mismo año aparece un artículo referente a Nordau y su método crítico: "Wagner embêté por Nordau" de Willy (Henry G.-V.) (número 107, 1 de octubre de 1893: 406-407). Estas publicaciones circularon en las mesas de redacción de la prensa porteña y en la sala de lectura del Ateneo de Buenos Aires. En su crónica dedicada a Verlaine, incluida en Los Raros, Darío alude, por ejemplo, a la defensa que Charles Ténib realiza del poeta francés frente a las acusaciones de Nordau: "Psychologie - Défense de Paul Verlaine" (La Plume, 15 de septiembre de 1894: 369-371). 
como a facultativos de la realidad (Lombroso, Bernard, Charcot, Lacassagne) y de la ficción (Sangrado, Purgón, Diafoirus, Bonhomet), a partir de los cuales se desarman y arman nuevos argumentos. De acuerdo con Rodrigo Caresani, en la obra de Darío se formula "una concepción del lenguaje literario como cita de citas o 'navegación de biblioteca' que trabaja en las posibilidades de la traducción y pauta esa distancia entre el importador y el portador inaugurada por el modernismo" (Caresani, 2017: 129130). La retórica de la enfermedad sirve aquí para desmontar las hipótesis de la crítica literaria cientificista. Darío no sólo traduce el archivo médico, sino que comenta ese otro saber desde una mirada artística que se emancipa de los condicionamientos culturales y de las dicotomías médico-psiquiátricas de su tiempo (normal/patológico, sano/enfermo, cuerdo/loco, productivo/improductivo).

En cuanto al plano elocutivo, uno de los procedimientos discursivos más recurrentes en la crónica es el de la figuración irónica, entendida aquí como una modalidad retórica caracterizada principalmente por el contraste de valores argumentativos y por su carácter negador de las prácticas discursivas institucionalizadas. ${ }^{14}$ De este modo, el proceder irónico cumple en el texto una función desestabilizadora del discurso médico, a la vez que crea un lector cómplice con la mirada artística. Así, por ejemplo, en el quinto segmento se observa el empleo de la figuración irónica para cuestionar el método analítico de Nordau:

Después de la diagnosis, la prognosis; después de la prognosis la terapia. Dada la enfermedad, el proceso de ella; luego, la manera de curarla. La primera indicación terapéutica es el alejamiento de aquellas ideas que son causa de la enfermedad. Para los que piensan hondamente en el misterio de la vida, para los que se entregan a toda especulación que tenga por objeto lo desconocido, "no pensar en ello" [...] Nordau pasando sobre el hegelianismo y el idealismo transcendental de Fichte en persecución del egoísmo morboso, explica etiológicamente la degeneración como un resultado de la debilidad de los centros de percepción o de los nervios sensitivos; cuando trata de la curación debe permitir que sus lectores abran la boca en forma de O... Receta: prohibición de la lectura de ciertos libros, y, respecto a los escritores "peligrosos", que se les aleje de los centros sociales, ni más ni menos como á los lazarinos y coléricos (Darío, 2015: 144-145).

La textualidad de la crónica desmonta el esquema narrativo del caso clínico mediante un discurso que apela a la figuración irónica de sus aparentes demostraciones. ${ }^{15}$

\footnotetext{
${ }^{14}$ Seguimos aquí algunas consideraciones propuestas por Pere Ballart sobre el funcionamiento de la figuración irónica. El teórico catalán precisa seis rasgos mínimos y complementarios que debe poseer y satisfacer todo discurso literario a fin de ser considerado o interpretado como irónico: 1) un dominio o campo de observación; 2) un contraste de valores argumentativos; 3) un determinado grado de disimulación; 4) una estructura comunicativa específica; 5) una coloración o motivación afectiva; y 6) una significación estética (Ballart, 1994: 311 ).

${ }^{15}$ Nouzeilles anota que, "en su forma escrita, el caso médico era un verdadero género narrativo a través del cual los enfermos se convertían definitivamente en pacientes y en pro-
} 


\section{El artista modernista y el discurso psiquiátrico}

El mecanismo retórico activa un contrasentido entre dos formas de ver: la artística y la médica. En el fragmento citado, el enunciador textual disimula su mirada crítica-artística a través de un discurso que trasluce cierta afectación o ingenuidad. De tal modo, la crónica establece un distanciamiento irónico con lo expuesto, para que sea el lector quien juzgue los argumentos esgrimidos por el médico. En ese sentido, si contrastamos el texto dariano con lo propuesto por Nordau en su tratado de nosología estética, se podrá observar con mayor claridad la mecánica de dicho proceder. En el segundo tomo de Degeneración, el médico sostiene que:

Los místicos, pero sobre todo los egotistas [entre los cuales incluía a artistas simbolistas y decadentes], y los pseudo-realistas que cultivan la porquería, son enemigos de la sociedad de la peor especie. Tiene ésta el estricto deber de defenderse contra ellos; los que como yo creen que la sociedad es la forma natural orgánica en la cual únicamente la humanidad puede vivir, prosperar y evolucionar hacia más altos destinos; los que consideran la civilización como un bien valioso y que merece ser defendido, esos deben inexorablemente aplastar con el pie la escoria anti-social (Nordau, 1902, t. II: 493).

La crónica despliega una postura crítica respecto a esta matriz discursiva, mostrando sus contradicciones y sus falsos presupuestos sustentados en una óptica eugenésica. Esto se materializa en el texto mediante el recurso irónico de la reductio ad absurdum. De esta suerte, los planteamientos de Nordau reducidos a sus principios básicos, desprovistos de su aparato argumental analógico y de su aparente taxonomía de tipos patológicos, con un claro sesgo moralizante, resultan escandalosamente ridículos. ${ }^{16}$

blemas clínicos. Fundamentalmente, lo que se narraba era la historia del descubrimiento de un diagnóstico; en otras palabras, se trataba del relato de una interpretación. Su organización a posteriori en cuatro secuencias básicas (etiología, diagnóstico, prognosis y tratamiento) oculta su verdadera matriz estructural" (Nouzeilles, 2000: 69).

${ }^{16} \mathrm{El}$ objeto de estudio clínico de Nordau era la sociedad y, más específicamente, el "estado de espíritu" de la sociedad francesa de fines del siglo XIX, a la que denominó con el término de fin de siècle. Para el médico: "El carácter común de numerosas manifestaciones contemporáneas, así como la disposición de espíritu fundamental que en ellas se revela, se resume en el término fin de siglo" (Nordau, 1902: 3). Según Nordau, quien opera bajo la lógica del discurso epidemiológico, París era el foco de irradiación de esta patología social y su lugar original de circulación. Apoya su definición de fin-de-siglo en la presentación de una serie de "casos", fragmentos de libros y periódicos franceses en donde se ha empleado el término, para llegar a una ley general: el estado de espíritu fin de siglo se determina por "el desprecio de las conveniencias y de la moral tradicionales" (Nordau, 1902: 9). Época de incertidumbre y confusión que se caracterizaría por la búsqueda de una revelación que dé orden al mundo. Para Nordau, este vacío espiritual que vive la sociedad es aprovechado por los artistas y escritores de fin de siglo para presentarse como los nuevos profetas (Nordau, 1902: 11). Nordau introduce una mirada conservadora frente al arte moderno, que rechaza lo estrambótico de la moda, la artificialidad, la excentricidad, lo ecléctico de las nuevas tendencias. Para el autor 
En suma, se puede concluir, a partir del análisis realizado, que la modernidad de la crónica dariana, sobre todo en sus etapas iniciales, reside en su carácter negador de los discursos normalizados. De este modo, la retórica de la enfermedad trazada en la galería de retratos anómalos que componen Los Raros sirve a Darío como instrumento de desmontaje de la episteme del discurso médico-psiquiátrico aplicado al dominio del arte y de la literatura. De igual forma, se puede afirmar que la apropiación del archivo médico que opera Darío se define por el empleo de un discurso que incide sobre la genialidad patológica como mecanismo de reacomodo de la escritura y en la creación de un nuevo espacio para la función del escritor. Asimismo, el examen del contexto de producción en que surge Los Raros permite documentar la progresiva medicalización del sistema estatal argentino, sobre todo a partir de 1880 . Dicho suceso es clave para comprender la injerencia del discurso médico-positivista en campos que exceden la práctica clínica, lo cual da paso al surgimiento de nuevos saberes especializados en el diagnóstico de las llamadas patologías sociales. En este orden de cosas, la circulación de tratados psiquiátricos que centran su atención en el campo artístico y en las figuraciones del artista enfermo o degenerado ameritarán las respuestas de múltiples escritores. La crónica-reseña que Darío dedica al comentario crítico de Degeneración de Max Nordau se inserta en dichos debates del fin de siglo. En ese sentido, la retórica de la enfermedad se transforma en instrumento estético de desestabilización del discurso de la "nueva crítica científica", mostrando la naturaleza incierta de sus diagnósticos médico-estéticos y su empleo aparente de las categorías provistas por el archivo clínico.

\section{Bibliografía}

Ayarragaray, Lucas

Pasiones. Estudios médico-sociales. Buenos Aires: Jacobo Peuser, 1893.

BALLART, Pere

Eironeia. La figuración irónica en el discurso literario moderno. Barcelona: Quaderns Crema, 1994.

Bruno, Paula

"Vida intelectual de la Argentina de fines del siglo xix y comienzos del siglo xx. Un balance historiográfico", en PolHis. Mar del Plata: Programa Interuniversitario de Historia Política, año 5, número 9 (2012), 69-91.

Caresani, Rodrigo Javier

"Entre la isla y el mundo: el cosmopolitismo del pobre en Rubén Darío", en Valeria Añón et al. (compiladores). Tropos, tópicos y cartografia. Figuras del espacio en la literatura latinoamericana.

de Degeneración, lo que buscan estos movimientos es provocar un efecto de asombro, que trae como consecución negativa una excitación nerviosa en la sociedad. 


\section{El artista modernista y el discurso psiquiátrico}

La Plata: Universidad Nacional de la Plata, Facultad de Humanidades y Ciencias de la Educación, 2017, 117-149.

DARÍO, Rubén

Azul.... Valparaíso: Excelsior, 1888.

"Páginas literarias - Un escritor americano en París - La crítica artística - Plausibles primicias - Sensaciones de arte - Liminar de Salvador Rueda - París - Biblioteca azul - G. Richard imprimeur-éditeur - Cuentos escogidos de autores franceses contemporáneos - Cuentos escogidos de autores castellanos - Garnier - París", en La Nación, Suplemento "Edición extraordinaria de noticias extrajeras" (11 de octubre de 1893), 2-3.

"Manicomio de artistas - Degeneración - La última obra de Max Nordau", en La Nación (8 de enero de 1894), 4.

Los Raros. Buenos Aires: La Vasconia, 1896.

Los Raros. Segunda edición, corregida y aumentada. Barcelona: Maucci, 1905.

El canto errante. Madrid: M. Pérez Villavicencio, Biblioteca Nueva de Escritores Españoles, 1907.

"Apuntaciones y párrafos", en Obras desconocidas de Rubén Darío. Escritas en Chile y no recopiladas en ninguno de sus libros. Edición de Raúl Silva Castro. Santiago de Chile: Prensas de la Universidad de Chile, 1934, 64-76.

Los Raros. Edición de Günther Schmigalle. Berlín: Tranvía, 2015.

Azul.../Cantos de vida y esperanza. Edición de José María Martínez. Madrid: Cátedra, 2016.

\section{ANÓNIMO}

"El Dr. Schimper - Nuestro corresponsal en Alemania - Datos biográficos — Sus viajes - su profesorado - Cómo se hizo periodista - Obras futuras", en La Nación (29 de junio de 1893), 1.

Foucault, Michel

De lenguaje y literatura. Barcelona: Paidós, 1996.

La arqueología del saber. Buenos Aires: Siglo Veintiuno, 2002.

El nacimiento de la clínica: una arqueología de la mirada médica. Buenos Aires: Siglo Veintiuno, 2008.

Los anormales. Buenos Aires: Fondo de Cultura Económica, 2014.

Gener, Pompeyo

Literaturas malsanas. Estudios de patología literaria contemporánea. Madrid: Fernando Fé, 1894. 


\section{Groussac, Paul}

"Introducción - La degeneración hereditaria", en José María Ramos Mejía. La locura en la historia. Buenos Aires: Lajouane, 1895, V-LVII.

GuYAU, Jean-Marie

El arte desde el punto de vista sociológico. Traducción de Ricardo Rubio. Madrid: Librería de Fernando Fé/Saenz de Jubera, Hermanos, 1902.

Huertas García-Alejo, Rafael

"Prólogo", en J. E. D. Esquirol. Memorias sobre la locura y sus variedades. Madrid: Dorsa, 1991, 9-23.

INGENIEROS, José

La psicopatología en el arte. Buenos Aires: L. J. Rosso, 1920.

Martínez, José María

"Los raros: arquitectura(s), jerarquías y filiaciones", en Zama. Número extraordinario. Homenaje a Rubén Darío. Buenos Aires: Instituto de Literatura Hispanoamericana, Universidad de Buenos Aires (2016-2017), 69-91.

Martínez Fernández, José

La intertextualidad literaria. Madrid: Cátedra, 2001.

Murillo, Susana

El discurso de Foucault. Estado, locura y anormalidad en la construcción del individuo moderno. Buenos Aires: Universidad de Buenos Aires, 1996.

Nietzsche, Friedrich

Más allá del bien y del mal. Preludio de una filosofia del futuro. Madrid: Alianza Editorial, 2005.

NORDAU, Max

Psico-fisiología del genio y del talento. Traducción de Nicolas Salmerón y García. Madrid: Saenz de Jubera, Hermanos, 1901.

Degeneración. Tomos I y II. Traducción de Nicolas Salmerón y García. Madrid: Librería de Fernando Fé/Saenz de Jubera, Hermanos, 1902.

Nouzeilles, Gabriela

"Narrar el cuerpo propio. Retórica modernista de la enfermedad", en Estudios. Revista de Investigaciones Literarias. Caracas: año 5, número 9 (1997), 149-176.

Ficciones somáticas. Naturalismo, nacionalismo y políticas médicas del cuerpo (Argentina 1880-1910). Rosario: Beatriz Viterbo, 2000.

Ramos Mejía, José María

Estudios clínicos de enfermedades nerviosas y mentales. Buenos Aires: Félix Lajouane, 1893. 


\section{El artista modernista y el discurso psiquiátrico}

Las neurosis de los hombres célebres en la historia argentina [1878-1882]. Buenos Aires: Biblioteca Nacional, 2013.

"Rubén Darío"

La Nación (15 de febrero de 1889), 1.

SALESSI, Jorge

Médicos, maleantes y maricas. Higiene, criminología y homosexualidad en la construcción de la nación argentina (Buenos Aires: 1871-1914). Rosario: Beatriz Viterbo, 1995.

SCHIMPER, Wilhelm

"Carta de Alemania - Un drama de Ibsen — 'El arquitecto Solness' — 'Entartung' — El último libro de Max Nordau - La degeneración y la histeria en la sociedad contemporánea - Patología de la pintura moderna - Escuelas estéticas y pandillas de ladrones Causas de la degeneración", en La Nación (lunes 6 de febrero de 1893a), 1.

"Carta de Alemania - El misticismo - Su historia natural y médica — Los simbolistas - Verlaine, alienado circular - El tolstoismo - Ricardo Wagner - Caracteres de su locura - 'Leitmotiv' y melodía perpetua - Formar paródicas del misticismo - Pelladan, Rollinat y Maeterlinck - La monomanía científica de Max Nordau — Cartas inéditas de Enrique Heine - Cariño del poeta a su madre - Una griseta parisiense en Hamburgo", en La Nación (lunes 9 de febrero de 1893b), 1.

Sobejano, Gonzalo

“"Épater le bourgeois' en la España literaria de 1900", en Biblioteca Virtual Miguel de Cervantes, 2009. Consultado en: www.cervantesvirtual.com/nd/ark:/59851/bmcrr2d0 $[15 / 01 / 2020]$.

SONTAG, Susan

La enfermedad y sus metáforas. El sida y sus metáforas. Barcelona: Debolsillo, 2016.

Stecher, Pablo von

La palabra médica en la Argentina 1890-1910: enfermos, simuladores y parias. Córdoba: Editorial Universitaria Villa María, 2017.

TERÁN, Oscar

Vida intelectual en el Buenos Aires fin-de-siglo (1880-1910). Derivas de la "cultura científica". Buenos Aires: Fondo de Cultura Económica, 2000.

Thorel, Jean

"Une nouvelle méthode de critique (1) - M. Max Nordau", en Revue Politique et Littéraire. Revue Bleue, número 7, tomo LII (12 de agosto de 1893), 208-214.

Vezzetti, Hugo

La locura en la Argentina. Buenos Aires: Paidós, 1985. 
WILDE, Eduardo

Curso de hïiene pública. Buenos Aires: Imprenta y librería de mayo de C. Casavalle, 1878.

Zavala Díaz, Ana Laura

"Retóricas de la enfermedad en el México porfiriano: el caso modernista", en Decires. México: Universidad Nacional Autónoma de México, Centro de Enseñanza para Extranjeros, volumen 10, números 10-11 (2007), 167-180.

"Hacia la construcción de una comunidad emocional letrada: polémicas modernistasdecadentistas en el México porfiriano", en Entre Caníbales. Lima: año 2, número 8 (2018), 93-110. 